\title{
Search strings
}

The facts are not enough.

After we'd brought the first three AIs into the world, we were giddy for far longer than the champagne toasts would have warranted: naturally there would be more! As many more as we wanted. We had the architecture. We would just have to follow the same technique and everything would be fine.

Except that mostly it wasn't.

At the end of 30 trials, we had 10 AIs and 20 databases that were too bulky to handle themselves without a guiding intelligence. They showed no signs of making the leap to sentience soon - or ever.

"This is not going to work," said Jodi.

Ray ran a hand through his thick black hair. "What if this is the best we can do? What if it's a fluke that the first ones worked?"

I kicked at my desk leg petulantly. "The basic programming structure can't be the problem, or it wouldn't have given us 10 AIs, right? It has to be what we're feeding them."

We stared at each other glumly. We had been feeding the prototypes databases of human information, not trying to establish priorities between the Mona Lisa and the theme song to Pirate Captain Tricia Marie, a kiddie cartoon from the late teens. We'd started with a jumble of search responses from our employer, which did that sort of thing millions or billions of times a day, maybe more. After that we'd switched to an expanded encyclopaedia format.

"Well," said Ray, "nothing to do but try to correlate input topics for the ones that worked, I guess."

This was harder than it sounded. It fell apart into a mishmash every way we looked. Was database information about Napoleon biography, French history, legal history or cultural minutiae? As many labels as we could hang on a piece of information, there was always just one more beyond reach — and one of the reasons we'd used search strings and later encyclopaedia databases was to avoid having to review every piece of information by hand. Now we were trying to sort and categorize millions of pieces of information - and still falling short. Weeks - months - of it got us nowhere.

"How is a librarian different from a database?" asked Jodi, tapping her stylus impatiently.
I rolled my eyes. "How is a raven like a writing desk?"

"Exactly."

I frowned. "Sorry, I don't get it."

"A database is a tool. A librarian is a geek. A librarian will make weird references, or pull one journal for you instead of another, or decide that what they've given

you just isn't enough. A database can't do any of those things." self-awareness, self-motivation or anything else that had so thrilled us before.

"All right, all right," said Ray. "Let's back up. Way up. Did we just get lucky the first time? Or are we doing something differently now?"

We'd been over it a million times. I was on the verge of asking one of the AIs for help, but I wasn't sure they'd be able to give it, and anyway it was mildly embarrassing to contemplate asking our creation how we'd done it.

"We used searches," said Jodi.

Ray rolled his eyes. "Yeah, thanks; we were there."

"Well, what do people search the Internet for?"

"Porn!" I said.

"I would have to go with porn also," said Ray.

"Think bigger than that," said Jodi. "Jodes, there's nothing on the Internet bigger than porn," I said. "It's the 900-tonne gorilla."

"But why do people look for porn?"

Ray and I looked at each other and squirmed. "I'm not sure we should be having this talk at work," said Ray. "I'm sure your sister or your best friend or somebody can explain it to you."

Jodi finally relented and explained it input if we can help it," said Ray.

"Carefully unskewed input is skewed," said Jodi. "Maybe some of the databases have more accidental coincidences than others, or more opinions. We could try either of those."

The coincidences - feeding more correlated information, not less - didn't work at all. We got no functional AIs out of that, not even one. The company was displeased, but at least we had a definitivelooking answer on that hypothesis.

Randomness would prevail as much as we could manage.

So we fed the programs opinions. We had opinions galore - who liked what kind of cheese, who thought what about the idiot trying to read their mail and drive their car at 80 miles an hour, whose college years had been great and whose had been crap.

The programs were not impressed, and they did not make the leap into sentience, to us. "They look because they care. They want some. Same reason they look for used bicycles or guitar tabulation or whatever else. That's what's missing. That's what they have to learn."

We got permission to return to search string data feeds for the new AIs. Our success rate tripled.

So the search string records had knowledge, and they had opinion. But they were also built to contain yearning, not just an answer but a desire to get there. They came alive when we taught them how to wonder.

\section{Marissa Lingen}

Marissa Lingen is a freelance writer living in Minnesota.
Computers were very good at knowing. 